\title{
RUBÉN DARÍO Y EL CONDE DE LAS NAVAS (CORRESPONDENCIA)
}

\section{Noel Rivas Bravo}

In this paper, Rubén Darío's and Conde de las Navas' letter-writing is studied in order to configure several not well known biographical aspects of the former.

Todavía carecemos de un epistolario completo de Rubén Darío. Su correspondencia, muy importante para conocer algunos aspectos desconocidos de su biografía, permanece dispersa por los numerosos países que el poeta visitara durante su errante vida y apenas ha sido publicada parcialmente y sin ningún rigor metodológico. Aquí presentamos reunidas por primera vez las cuatro cartas que se conservan del poeta nicaragüense dirigidas a su amigo el Conde de las Navas, Juan Gualberto López-Valdemoro (Málaga, 1855-Madrid, 1935). Este personaje, Bibliotecario Mayor del Palacio Real, narrador, historiador y periodista, considerado por Demidowicz como un "genio menor de las letras hispánicas", fue admirado y respetado por sus coetáneos, aunque el tiempo no ha sido generoso con su obra que permanece en piadoso olvido. Escritor castizo, ameno y elegante, amó a España y a su patria chica Andalucía a la que consagró la mayor parte de sus innumerables escritos.

La amistad y el aprecio que unieron a Darío con el Conde, no estudiada hasta ahora, se manifiesta claramente en la correspondencia que ambos sostuvieron a lo largo de muchos años y en los respectivos reconocimientos y elogios que se prodigaron. La primera carta que el nicaragüense dirigió al Conde está fechada en Madrid, Hotel Santa Cruz, el 24 de abril de 1905. En ella le envía sus felicitaciones por la publicación del libro Don Juan Valera. Apuntes al natura ${ }^{2}$ recuerda el momento en que se conocieron y nos confirma un dato ya conocido por los estudiosos darianos: que nuestro poeta fue asiduo visitante, desde su primer viaje a España (1892), de la famosa tertulia que don Juan Valera tenía en su casa de habitación situada en la Cuesta de Santo Domingo. "Me invitó don Juan a sus reuniones de los viernes en donde me hice de excelentes conocimientos: el duque de Almenara Alta, don Narciso Campillo y otros cuantos que ya no recuerdo", escribió Darío años más tarde", incurriendo en una extraña confusión, porque en la crónica "Novelas y novelistas" ya había anotado que las reuniones en casa de Valera eran los sábados y no los viernes, como en efecto registra la historia literaria: "Sus sábados han sido famosos entre las gentes de letras.

\footnotetext{
${ }^{1}$ J.P. Demidowicz: "El conde de las Navas: un genio menor", Revista de literatura, Madrid, Consejo Superior de Investigaciones Científicas, t, LV, págs. 585-589.

${ }^{2}$ Madrid, Fernando Fé, 1905.

${ }^{3}$ R. Darío: La vida de Rubén Darío escrita por él mismo, Barcelona, Casa Editorial Maucci, 1915, p.122.
} 
La muerte ha raleado algo el grupo de sus contertulios"4. El texto de la carta reproducida por Demidowicz ${ }^{5}$ dice así:

Hotel Santa Cruz.

Señor y muy distinguido amigo.

Permítame Vd. que le envíe mis más cordiales felicitaciones por su trabajo sobre don Juan Valera, que acabo de leer. Es lo mejor que he visto sobre el maestro. Recuerdo que él fue quien me presentó a Vd. en una de aquellas noches en que tanto talento se esparcía en su salón.

Con mis más afectuosas expresiones queda de Vd. affmo. Amigo q.b.s.m.

Rubén Darío.

24 de abril de 1905.

Casi un año después tenemos otra noticia de las estrechas relaciones entre ambos amigos. Oliver Belmás ${ }^{6}$ transcribe un telegrama fechado en 1906, que dirige el Conde de las Navas a Darío confiándole su satisfacción por la cálida acogida y hospitalidad que los poetas y escritores de Palma de Mallorca habían ofrecido al nicaragüense en su primera visita a la isla durante uno de sus periodos de convalecencia. Como se sabe, aquí tuvo lugar el célebre banquete de despedida que el 2 de marzo de este año reunió alrededor del autor de "Valldemosa" a 40 comensales representantes de la flor y nata de la intelectualidad mallorquina. El telegrama dice:

En espiritu y verdad le acompaña su devoto. Conde de las Navas.

Y en ese mismo año, el 21 de diciembre, el Conde le escribe de nuevo a Darío, quien por entonces realizaba un apoteósico viaje por Nicaragua después de quince años de ausencia. Recordemos que fue en esta memorable ocasión cuando el gobierno liberal de José Santos Zelaya reconoció el valor de la inmensa personalidad de nuestro poeta nombrándole Ministro Plenipotenciario ante el gobierno de España. Veamos el fervoroso mensaje que recibió del Conde:

El Bibliotecario Mayor de S. M.

Excmo. Sr. D. Rubén Darío.

Mi muy ilustre amigo: A sus dos gratos telegramas respondo: que me alegro, como de las propias, con las alegrías patrióticas de Nicaragua y ya me canso de aguardar

\footnotetext{
${ }^{4}$ R. Darío: España contemporánea, París, Garnier-Hermanos, 1901, p.217.

5 J. P. Demidowicz: "El Conde de las Navas y los contertulios de don Juan Valera", Cuadernos Hispanoamericanos, Madrid, Instituto de Cooperación IberoAmericana, n² 241, enero, 1970, pág. 164.

${ }^{6}$ A. Oliver Belmás: Este otro Rubén Darío, Barcelona, Aedos, 1960, pp. 42.
} 
con los brazos abiertos al insigne Ministro Plenipotenciario en Madrid de la simpática República.

Profundamente agradecido estoy al doble y cariñoso recuerdo de usted.

Mande a su admirador y amigo.- El C. de las Navas.

Cinco años más tarde encontramos de nuevo otra carta de Rubén dirigida al Conde. Su contenido nos hace vislumbrar que el aristócrata andaluz sirvió no pocas veces de intermediario en las relaciones cordiales que el nicaragüense mantuvo con el rey de España. Fechada en París el 18 de abril de 1911, Darío le agradece el envío de los dos tomos que integran el Catálogo de la Real Biblioteca (1911) y que "por bondad de Su Majestad el rey don Alfonso XIII" había recibido con la siguiente dedicatoria escrita por el mismo Conde: "Quiere el augusto Señor que tal presente signifique para usted prueba y recuerdo de la admiración que le inspira como gran poeta de nuestra lengua" ${ }^{\text {. }}$ Y una vez más Darío reitera su afecto y admiración por el Monarca de quien ya se había ocupado en dos de sus crónicas: "El rey"8 y Alfonso XIII ${ }^{9}$. No olvidemos asimismo que Darío presentó sus credenciales ante el distinguido gobernante en un singular acto protocolario cuando se incorporó como Ministro de Nicaragua en la capital del reino (Mayo, 1908). A continuación insertamos el texto de la carta reproducida por Ana María Hernández de López ${ }^{10}$ :

Sr. Conde de las Navas.

Madrid.

Mi señor y muy distinguido amigo

Ruégole dar las gracias a S.M. por el envío que graciosamente se ha servido remitirme por su honroso medio. Suplícole diga a S.M. que no solamente agradezco este regalo sino que singularemente encargaré para que escriba, sobre estos valiosos documentos, a un especialista, Monsieur Henri Lorin, profesor de la Universidad de Burdeos

Es demás decir que a S.M. estoy agradecidísimo por esta manifestación de su recuerdo afectuoso. Yo siempre, en toda clase de artículos y trabajos, he procurado presentar al Rey en su faz simpática: trabajador, tradicional, bello, noble y digno de los cuadros y de las estatuas acestrales.

Usted comprende, mi querido amigo, que en una revista como la que yo dirijo -y sobre todo conociendo mi carácter- no vamos hacer adulación ni rastacuerismo: así que puede usted asegurar a S.M. que todo lo que diga aquí -como no sea llevado por el gran cariño personal que le tengo, naturalmente correspondido por las manifestaciones que él ha

\footnotetext{
${ }^{7}$ Vid., Rubén Darío: “Libros regios”, publicado en La Nación, Buenos Aires, 3 de septiembre de 1911.

${ }^{8}$ España contemporánea, Op.cit., págs. 132-142.

${ }^{9}$ R. Darío: Alfonso XIII, Madrid, Biblioteca Ateneo de Autores Americanos, 1909.

${ }^{10}$ A. M. Hernández de López: El Mundial Magazine de Rubén Darío, Madrid, Ediciones Beramar, 1989, pág. 121.
} 
tenido conmigo- será brillantemente expresado por firmas que siempre llevarán mi aprobación. Ruégole diga a S.M. esto.

\section{Rubén Darío}

Por otra parte, Alberto Ghiraldo ${ }^{11}$ reproduce las otras dos cartas del poeta nicaragüense al Conde de las Navas. En una de ellas fechada el 8 de junio de 1911 le agradece el envío de dos de sus cuentos que se publicarían en la revista Mundial Magazine del mismo año: "La tela de Pepa López" en el número de agosto y "Martas y gatos" en el de diciembre. Según parece el profesor Henri Lorin, recordado en la carta anterior, no se ocupó de comentar los tomos del Catálogo de la Real Biblioteca, porque el nicaragüense le promete al Conde encargarse personalmente de ello, promesa que cumplió escribiendo el artículo "Libros regios" al que ya hemos aludido en nota a pie de página. Veamos ahora el texto de la carta:

8 de junio de 1911

Sr. Conde de las Navas.

Madrid.

Mi señor y muy distinguido amigo:

Exquisito regalo, para los lectores de Mundial, con sus dos cuentos recibidos. Ellos serán convenientemente ilustrados, lo mejor que se pueda. He encargado que le remitan pruebas.

En La Nación, de Buenos Aires, me ocuparé, largamente, de los dos volúmenes sobre la Real Biblioteca que recibí.

Con todo afecto y estimación, quedo s.s.s. y amigo, Rubén Dario.

La cuarta carta que envió Rubén al escritor andaluz "en papel timbrado, a dos tintas, roja y negra, propio de la revista intitulada Mundial Magazine"12, está fechada el 21 de diciembre de 1911. En ella le pide disculpas a causa de la falta cometida por los cajistas en el número de Navidad de Mundial donde apareció, como dijimos anteriormente, el cuento "Martas y gatos". En efecto, la falta a que ambos amigos aluden se refiere a que, en la sección "Nuestros colaboradores" firmada por Rubén Darío en la que se ocupa de la obra de cada uno junto a una breve bibliografía y su respectiva foto, sólo aparece la fotografía del Conde sin ninguna mención a su obra y su persona. Y es seguramente para reparar esta omisión que Rubén le anuncia "una amplia satisfacción" lo que hizo con verdadero aprecio y conocimiento en el artículo "El Conde de las Navas", recogido en Letras ${ }^{13}$. (Curiosamente en este trabajo Darío hacía al Conde digno acreedor por su méritos

\footnotetext{
${ }^{11}$ A. Ghiraldo: Epistolario, Madrid, Mundo Latino, 1926, págs. 123-124.

${ }^{12}$ El Conde de la Navas: La educación de un rey «a nativitate», Madrid, Gráficas Reunidas, 1921, pág. 36.

${ }^{13}$ París, Garnier-Hermanos, s/f, (1911), págs. 187-195.
} 
intelectuales y literarios de formar parte de los académicos de la lengua, nombramiento que al fin de cuentas obtuvo en 1924). Y termina la carta sugiriéndole escribir un singular artículo sobre el rey Alfonso XIII, artículo que por entonces el Bibliotecario Mayor no llegó a redactar, pero cuya anécdota recordaría años más tarde: "No llegué a complacer al gran poeta, a quien debí cariñosísimas atenciones en varios impresos de Ambos Mundos, periódicos y libros; pero me hice cargo desde entonces de que si la Pedagogía interesa de verdad o por moda, la educación de nuestro Monarca podía ser capaz de despertar, fijándola, la atención de los americanos españoles"14. Tal vez convenga recordar aquí que Darío dedicó posteriormente en la revista Mundial una de sus Cabezas a "S.M. el Rey Don Alfonso XIII"15, la tercera de sus colaboraciones sobre el monarca español. El texto de la carta es como sigue:

Excmo. Sr. Conde de las Navas.

Madrid.

Mi señor y cordial amigo:

Desolado advertí, antes que usted, la falta que me señala en el Mundial de Navidad. ;Si viera usted con todo lo que tengo que luchar para evitar esas cosas, y otras, en una oficina aún no bien organizada y en una imprenta en que no hay un solo cajista español! Pero, en fin, yendo al caso: Usted tendrá una amplia satisfacción en uno de los números próximos, pues me ocuparé de usted y su obra exclusivamente. ¿Querría usted escribir un artículo sobre Don Alfonso estudioso, es decir, sobre cuando estudiaba; o Don Alfonso y los libros, o algo así, que aparte, por un momento, de los lectores, la idea de ser únicamente sportman? El trabajo tendría, naturalmente, que venir acompañado de fotografías.

Quedo, deseándole feliz año nuevo, su viejo amigo,

Rubén Darío.

En definitiva, la amistad de Darío con el Conde de las Navas fue amplia, generosa y perdurable. Desde el año de 1892 en que se conocieron hasta 1914 cuando el poeta abandonó España para siempre, sus relaciones se mantuvieron dentro de la más sincera cordialidad. Así lo testimonia el nicaragüense cuando afirmaba que el Conde las Navas es "una de las más finas amistades que conservo desde entonces" 16.

\footnotetext{
${ }^{14}$ La educación de un rey... Op. cit., págs. 36-37.

${ }^{15}$ Marzo, 1912.

${ }^{16}$ La vida de Rubén Darío escrita por él mismo, Op. cit. p.123.
} 